\title{
The Role of Temporary Fecal Diversion
}

\author{
Amy L. Lightner, MD ${ }^{1}$ John H. Pemberton, MD ${ }^{1}$ \\ ${ }^{1}$ Division of Colon and Rectal Surgery, Department of Surgery, Mayo \\ Clinic College of Medicine, Rochester, Minnesota \\ Clin Colon Rectal Surg 2017;30:178-183.
}

\begin{abstract}
Address for correspondence John H. Pemberton, MD, Division of Colon and Rectal Surgery, Department of Surgery, Mayo Clinic College of Medicine, Gonda 9S, 200 First St. SW, Rochester, MN 55905 (e-mail: pemberton.john@mayo.edu).
\end{abstract}
Abstract
Keywords
- diverting ostomy
- anastomotic leak
- loop ileostomy
- colostomy
- stoma

The use of temporary fecal diversion is of great importance to tenuous anastomosis, immunosuppressed patient, or actively infected patient. Its use protects newly constructed intestinal anastomoses from being the culprit of pelvic sepsis or systemic illness. Thus, potential morbidity and mortality can be averted. However, its appropriate or optimal use is often debated. We herein discuss the evidence for when to best use a diverting stoma for colorectal, coloanal, and ileoanal anastomoses. We also discuss the importance of considering a temporary diverting stoma in the setting of high-dose immunosuppression (e.g., transplant patients or inflammatory bowel disease), active infection, or upon creation of ileal pouch-anal anastomosis. Lastly, we discuss the advantages and disadvantages of a loop ileostomy versus colostomy for temporary diversion of fecal contents.
The role of temporary fecal diversion remains an area of controversy among surgeons for patient-specific scenarios. Its use can be of great importance in protecting tenuous anastomoses in the pelvis, for patients who are immunocompromised, or for patients who are acutely septic. Although fecal diversion does not prevent an anastomotic leak, it does avert the potential morbidity and mortality from an anastomotic leak. And, for patients undergoing ileal pouch-anal anastomosis (IPAA), the lifelong function and preservation of the pouch can be optimized by preventing pelvic sepsis. Diversion is not without consequence, however. Patients are subjected to additional operations and may develop small bowel obstructions related to the diverting ostomy, acute kidney injury due to a high stoma output, a parastomal hernia, or complications at the time of ostomy reversal. However, all these disadvantages need to be carefully weighed against the potential consequences of the anastomotic leak in a variety of anatomical scenarios and patient-specific scenarios. We herein discuss the evidence for when to best use a diverting stoma for colorectal, coloanal, and ileoanal anastomoses. We also discuss the importance of considering a temporary diverting stoma in the setting of highdose immunosuppression (e.g., transplant patients or inflammatory bowel disease [IBD]), active infection, or upon creation of IPAA. Lastly, we discuss the advantages and disadvantages of a loop ileostomy versus colostomy for temporary diversion of fecal contents.

\section{Tenuous Anastomoses}

An anastomotic leak is the dreaded complication after a colorectal resection with significant morbidity ${ }^{1}$ and mortality (6-22\%). ${ }^{2}$ One can anticipate that anastomotic leakage may occur in a medically fragile patient, or after a technically difficult operation, or if intraoperative adverse events were present. However, anastomotic leakage also occurs in patients with no obvious risk factors. ${ }^{3}$ The difficulty in predicting anastomotic leakage has generated several studies in recent years with the aim of identifying risk factors for anastomotic leakage. ${ }^{2-5}$ Extensive literature has described many risk factors for an anastomotic leak including male gender, smoking, obesity, alcohol use, preoperative steroids, longer duration of operation, preoperative transfusion, contamination of the operative field, case volume of rectal surgery, ASA (American Society of Anesthesiologists) class III or IV, and distance from the anal verge. ${ }^{6-13}$
Issue Theme Intestinal Stoma; Guest Editor: Michael F. McGee, MD, FACS, FASCRS
Copyright $\odot 2017$ by Thieme Medical Publishers, Inc., 333 Seventh Avenue, New York, NY 10001, USA. Tel: +1(212) 584-4662.
DOI https://doi.org/ 10.1055/s-0037-1598158. ISSN 1531-0043. 


\section{Low Colorectal Anastomosis}

In the era of increased sphincter sparing surgery for rectal cancer, increasingly distal anastomoses are being performed in the setting of neoadjuvant chemotherapy and radiation. Several studies have looked at diversion at the time of low anterior resection (LAR). Matthiessen et $\mathrm{al}^{14}$ performed a randomized controlled trial (RCT) to look at the symptomatic anastomotic leak rate following LAR for rectal cancer with and without a defunctioning stoma. Among 234 patients who underwent an LAR, the overall symptomatic leak rate was $19.2 \%$; patients randomized to a defunctioning stoma had a $10.3 \%$ leak rate versus $28 \%$ in those without a stoma, and the need for urgent abdominal reoperation was $8.6 \%$ in patients with a stoma versus $25.4 \%$ in those without. The authors therefore concluded that a defunctioning loop stoma decreased the rate of symptomatic anastomotic leakage among patients undergoing an LAR for rectal cancer. A 6year longitudinal follow-up after the initial LAR found that $19 \%$ of patients received a permanent stoma within the study period, and the risk of permanent stomas was significantly higher in patients with symptomatic anastomotic leakage versus those without (56 vs. $11 \%$ ). ${ }^{1}$ The same group later published their results that a defunctioning stoma after an LAR does not affect anorectal function evaluated at 1 year, further supporting the use of a temporary stoma. ${ }^{15}$ Another group from Germany performed an RCT of 256 patients undergoing an LAR to evaluate the utility of a diverting loop ileostomy. The group found 12 leaks (10\%) versus 3 leaks $(2 \%)$ in the nondiverted group and the diverted group, respectively. Two patients (17\%) without an ostomy who leaked were taken back to the operating room for Hartmann's procedure, whereas all patients who were diverted and who leaked recovered without the need to reoperate on the anastomosis. ${ }^{16}$ Another smaller RCT performed in parallel by a group in Germany randomized 34 patients to stoma versus nonstoma. ${ }^{17}$ The symptomatic leak rate was significantly higher in the nonstoma group (37.5\%) than in the stoma group (5.5\%), and in all cases of leaks in the nonstoma group, reoperations were necessary. ${ }^{17}$

Several meta-analyses of these RCTs have been performed, confirming the finding that diversion is preferred following LAR for rectal cancer. The most recent meta-analysis included the aforementioned four RCTs in addition to nine additional nonrandomized studies with a total population of 8,002 patients, of whom 3,562 had a protective stoma and 4,440 did not. The meta-analysis demonstrated that the absence of a protective stoma was associated with a significantly higher incidence of anastomotic leak and reoperation. This underscored the significant advantage conferred by a protective stoma in patients undergoing LAR. ${ }^{18}$

\section{Coloanal Anastomosis}

When rectal cancers abut the pelvic floor near the anorectal ring, coloanal anastomosis may be indicated. This ultralow anastomosis, performed either hand-sewn or stapled depending on the precise location of the tumor, is nearly uniformly diverted with little controversy. In general, the primary concern of diverting a patient with a coloanal anastomosis is anal stricture, which can occur in up to $8 \%$ of patients. ${ }^{19}$ However, diversion alone is not the primary cause of anal stenosis. Neoadjuvant radiation therapy has been reported to increase the stricture rate of coloanal anastomoses, ${ }^{20,21}$ and permanent diversion rates in patients after coloanal anastomosis, in the setting of radiation therapy, have been reported as high as $24 \%{ }^{21}$ Since the anastomoses are often too low for repeat resection, strictures are treated with repeated dilations and ileostomy takedown. ${ }^{19}$

\section{Ileorectal Anastomosis}

Ileorectal anastomoses have a high risk of leak, up to 23\%, which is significantly higher than colorectal or ileoanal anstomosis. ${ }^{22}$ Most of the literature regarding ileorectal anastomoses comes from patients with IBD. Before the development of the IPAA in the 1980s, patients with ulcerative colitis (UC) who did not want an end ileostomy were offered the option of an ileorectostomy. Additionally, patients with rectal sparing Crohn's colitis may undergo ileorectostomy if medical management fails. The reported leak rate from this patient population undergoing ileorectostomy is 2 to $7 \%$ with diverting ileostomy at the surgeon's discretion. ${ }^{23-27}$ The majority of patients in these series who ended up with a permanent stoma experienced a flare of the underlying disease and not an anastomotic complication.

In addition, patients undergo ileorectostomy for slow transit constipation or familial adenomatous polyposis (FAP), or other disease processes in addition to IBD. A study comparing the leak rates following ileorectostomy by patient diagnosis found a leak rate of $4.2 \%$ among patients with colonic inertia, $1 \%$ among patients with Crohn's disease (CD), and $0 \%$ among patients with FAP or neoplasia. ${ }^{28}$ Other studies have also noted a significantly higher leak rate among patients undergoing subtotal colectomy with ileorectal anastomosis for delayed transit or colonic inertia, implying the disease process may play a role. ${ }^{22}$

\section{Special High-Risk Scenarios}

\section{Immunosuppressed Patients}

Immunosuppressed patients are considered an at-risk patient population after rectal anastomoses for two reasons. First, a myriad of immunosuppressive medications have been implicated in delayed or impaired wound healing. Second, immunosuppressed patients are less likely to tolerate an anastomotic leak. Several patient populations are considered immunosuppressed, including HIV patients, transplant patients, and any patients taking chronic steroids. We will focus our discussion on solid organ transplant patients and patients with IBD.

Solid organ transplant recipients and patients with IBD are often maintained on a multitude of immunosuppressive medications including steroids, biologics, cyclosporine, azathioprine, tacrolimus, and sirolimus. Of the many classes of therapeutics, steroids are the mainstay of most regimens. More than $90 \%$ of solid organ transplant patients are maintained on steroids, and up to $28 \%$ of patients with CD and $22 \%$ of patients with UC are steroid dependent. ${ }^{29}$ Since steroids 
and biological therapies are the most commonly administered drugs for colorectal surgery patients with organ transplantation or IBD, these have been the most studied regarding their perioperative use and risk of an anastomotic leak.

\section{Corticosteroids}

Corticosteroids exert immunomodulatory and anti-inflammatory effects through the inhibition of antigen processing, T-cell activation, macrophage function, and cytokine production. Due to the inhibitory effect on the inflammatory response, systemic corticosteroid therapy is known to impair wound healing in several clinical scenarios. Thus, steroid use becomes an important consideration in the decision of whether or not to divert an intestinal anastomosis.

The effect of steroids on anastomotic healing remains a controversial topic. Several studies have concluded that systemic corticosteroid treatment is not associated with an increased rate of anastomotic leaks or infectious complications, ${ }^{30-33}$ whereas others have reported an increased anastomotic leak rate. ${ }^{34-37}$ A systematic review attempting to resolve the disparity of opinions reported an anastomotic leak rate of $6 \%$ among patients receiving steroids versus $3 \%$ in those who did not. Despite this being a nonsignificant difference, the authors suggested using caution in lower gastrointestinal surgery in the setting of preoperative steroid use. $^{38}$

\section{Biological Therapy}

Biological therapies have grown to play a significant role in the treatment of IBD. The dominant, and initial class of biologics, are the tumor necrosis factor- $\alpha$ (TNF- $\alpha$ ) inhibitors including infliximab, adalimumab, certolizumab, and golimumab. Recently, several additional biological drugs have been approved for the treatment of IBD that work through different anti-inflammatory mechanisms such as blocking integrins (natalizumab and vedolizumab) or interleukin (IL)12/23 (ustekinumab). ${ }^{39}$

The most well-studied biological therapy is infliximab. The initial studies of infliximab among IBD patients showed an increased risk of opportunistic infections and sepsis. ${ }^{30}$ This generated concern that surgical patients receiving infliximab would have increased postoperative infectious and anastomotic complications. Thus, several studies evaluating infliximab's contribution to postoperative morbidity followed. Some failed to demonstrate a significant increase in anastomotic leak rates among patients receiving infliximab prior to surgery, ${ }^{30,40,41}$ whereas others noted an increase in anastomotic complications among patients with $\mathrm{CD}^{42}$ and $\mathrm{UC}{ }^{43}$ and early pouch-specific complications following IPAA. ${ }^{44}$ Due to these mixed results, meta-analyses were conducted. One found no conclusive evidence that antiTNF treatment increased anastomotic complications, ${ }^{45}$ whereas another found the therapy did increase the rate of anastomotic complications. ${ }^{46}$ Unfortunately, this remains a controversial topic and requires surgeons to use their own judgment when operating on a patient who has received recent biological therapy. And, as new biological therapies are approved by the U.S. Food and Drug Administration, further study will be needed to evaluate their potential impact on postoperative complications.

With the literature in flux, exercising intraoperative judgment of whether to divert or not becomes important; patients who are solid organ transplant recipients, or IBD patients with refractory medical disease on several immunosuppressive agents, will likely not have the medical reserve to tolerate a leak, and thus it is probably wise to divert such patients.

\section{Active Infection or Gross Spillage}

Active infections, such as peritonitis from diverticular disease or gross spillage from a gunshot wound, have historically been indications for Hartmann's procedure without formation of a primary anastomosis. However, the recent trauma literature has supported performing a primary anastomosis with diversion even in the setting of gross contamination. ${ }^{47}$ In parallel, literature regarding operative strategy for diverticulitis with peritonitis had similar findings-primary anastomosis with diversion was preferred to Hartmann's procedure and end colostomy ${ }^{48,49}$ since Hartmann's procedure was associated with a higher complication rate (44\%) and mortality rate (1.7\%). ${ }^{50,51}$ Additionally, a systematic review of 15 studies on the topic of diverticulitis with peritonitis concluded that primary anastomosis with diversion was preferred over Hartmann's procedure due to decreased mortality in the emergent setting. ${ }^{52}$ The trauma literature and diverticulitis literature thus share common findings: decreased mortality with primary anastomosis and diversion as compared with Hartmann's procedure, decreased rate of permanent ostomy with primary anastomosis and diversion as compared with Hartmann's procedure, and diversion among all patients who are given a primary anastomosis at the time of the operation.

\section{Ileal Pouch-Anal Anastomosis}

IPAA is the procedure of choice in patients with UC and FAP since it removes the offending disease process while maintaining intestinal continuity. ${ }^{53}$ Because the operation includes colectomy, proctectomy, ileal pouch formation, and potential diversion, it has been described in a single-, two-, or threestage fashion. A single-stage IPAA, proctocolectomy with ileal pouch formation performed as one operation without ileal diversion, has been reported in several series. It has the advantage of a single operation as opposed to two or three, decreased complications related to diverting ileostomies, and decreased incidence of anal strictures. ${ }^{54,55}$ Some single-center series have reported no difference in anastomotic leak rates or pouch complications with single-stage versus two- or threestage IPAA. ${ }^{54,56}$ One report noted that if patients do experience a leak, sepsis can be controlled without an operation. ${ }^{57}$ Some authors advocate the use of single-stage IPAA in carefully selected patients (e.g., no tension at anastomosis and no prolonged use of steroids), ${ }^{55,56,58}$ and one group even concluded this regardless of reporting a higher leak rate without diversion. ${ }^{56}$ It is important to note that most of these studies 
were conducted prior to the introduction of biological therapy. Thus, patients were on less immunosuppressive medication and potentially had decreased disease severity at the time of operation. Today, given the amount of aggressive immunosuppression given to nearly all patients with UC, single-stage IPAA is not indicated because the lack of diversion puts the patient at high risk for early pouch-related anastomotic complications ${ }^{44}$ and pelvic sepsis (the leading risk factor for pouch excision ${ }^{59}$ ), and postoperative morbidity following pouch excision. ${ }^{60}$

A two-stage IPAA consists of proctocolectomy, IPAA, and diversion. Diversion has been shown to improve septic complications related to a leak ${ }^{61}$ and to decrease the number of anastomotic complications. ${ }^{62}$ A three-stage IPAA, which starts with a total abdominal colectomy, rectal oversewing or rectal mucous fistula, and end ileostomy, initially gives patients an opportunity to wean off immunosuppressive medications and recover their wound healing capabilities before undergoing a pelvic dissection with proctectomy and creation of an ileal pouch. However, some groups have shown no difference in infectious complications between patients who are on systemic steroids and those who are not and advocate that preoperative systemic steroid therapy does not necessarily warrant a threestage approach. ${ }^{33,63-65}$ Similarly, some centers argue that preoperative anti-TNF- $\alpha$ therapy in patients with UC has not and should not increase the number of three-stage pouches. ${ }^{33,66,67}$ Additionally, one large single-center study documented that a three-stage IPAA did not have a lower anastomotic leak rate as compared with a two-stage IPAA, and in fact had a higher rate of anal stricture. ${ }^{33}$ This group concluded that a three-stage IPAA may be overused in patients with UC.

However, it is important to remember that an ileal pouch involves a tenuous anastomosis to the anus, which is, in addition, usually double stapled. Pouch sepsis related to an anastomotic leak results in significant morbidity and is the leading cause for pouch excision. ${ }^{59}$ Pouch excision results in a permanent end ostomy without a chance for a pouch revision or future restoration of intestinal continuity in the majority of patients and can result in significant morbidity due to chronic wound complications. ${ }^{60}$ Additionally, pouch sepsis related to anastomotic leaks has been shown decrease quality of life as measured by the overall Cleveland Global Quality of Life score. ${ }^{68}$ Thus, in the era of biological medications, when many IBD patients are treated with a "cocktail" of immunosuppressive medications, a three-stage approach is being employed by many surgeons to prevent pouch sepsis and its associated complications. While the disadvantages of a three-stage operation include additional operations, small bowel obstructions, and readmissions for dehydration from high ileostomy output, these are arguably less devastating than pouch sepsis.

\section{Loop lleostomy versus Colostomy}

Several meta-analyses have compared loop ileostomy to loop colostomy for fecal diversion following a colorectal or coloanal anastomosis. ${ }^{69-73}$ A Cochrane Database Review in 2007 examined five studies that evaluated the safety and effectiveness of a loop ileostomy versus loop transverse colostomy for temporary diversion. Although the authors did not find ileostomies superior to colostomies, they did find significantly higher rates of stoma prolapse among the loop colostomy group, suggesting a benefit to ileostomy. Tilney et $\mathrm{al}^{73}$ looked at seven studies including three RCTs, and found that loop ileostomy may be preferable, due to decreased wound infections and overall complication rates, despite higher outputs. Güenaga et $\mathrm{al}^{70}$ looked at five RCTs and found a significantly higher rate of stoma prolapse among diverting loop colostomies. Rondelli et $\mathrm{al}^{72}$ looked at sphincter-saving surgery for the treatment of middle and low rectal cancer to compare the use of a diverting loop ileostomy versus colostomy. They looked at 12 comparative studies including five RCTs and found that among 1,529 patients, a loop ileostomy reduced the risk of prolapse at the stoma site, hernia after stoma closure, and risk of sepsis, but was associated with a higher risk of bowel obstruction after stoma closure and dehydration due to high stoma output. Chen et $\mathrm{al}^{69}$ looked at 12 studies, of which five were RCTs, and found that each type of diversion had its own advantages and disadvantages and could not conclude superiority of one over another.

Overall, the majority of studies conclude that loop ileostomies and colostomies are equivalent functionally. The several studies comprising the meta-analysis consistently suggest that the disadvantages of a loop ileostomy are the potential for high output resulting in acute kidney injury and small bowel obstruction due to adhesive disease while the disadvantages of a diverting colostomy are the rate of parastomal hernia formation and prolapse. Importantly too, loop colostomy, if performed in the sigmoid colon, decreases the options available for reconstruction in the pelvis. A loop transverse colostomy is notoriously difficult to manage compared with an ileostomy. Also, closure of a loop colostomy can be a major procedure requiring opening the abdomen, something that is a rare occurrence when closing a loop ileostomy.

\section{Conclusions}

The effectiveness of proximal diversion whether achieved by loop ileostomy or colostomy remains controversial. Most studies have focused on determining if diversion prevents an anastomotic leak or mitigates the consequences related to a leak. Moreover, potential added morbidity, including volume depletion with acute kidney injury, small bowel obstruction in up to a third of patients, ${ }^{74}$ readmission in nearly a fifth of patients, and complications with ostomy closures in another fifth of patients, ${ }^{75,76}$ need to be factored into any decision to construct a diverting stoma. There is reasonably sound data supporting a decision to divert patients undergoing LAR, coloanal anastomosis, emergent surgery for diverticulitis, and formation of IPAA; diversion likely does not prevent but rather lessens the impact of an anastomotic leak. It is therefore important that the surgeon weighs the risks and benefits of constructing a stoma while remembering that the consequences of leak and resulting pelvic sepsis are dire. 


\section{References}

1 Lindgren R, Hallböök O, Rutegård J, Sjödahl R, Matthiessen P. What is the risk for a permanent stoma after low anterior resection of the rectum for cancer? A six-year follow-up of a multicenter trial. Dis Colon Rectum 2011;54(1):41-47

2 Rullier E, Laurent C, Garrelon JL, Michel P, Saric J, Parneix M. Risk factors for anastomotic leakage after resection of rectal cancer. $\mathrm{Br}$ J Surg 1998;85(3):355-358

3 Law WL, Chu KW. Anterior resection for rectal cancer with mesorectal excision: a prospective evaluation of 622 patients. Ann Surg 2004;240(2):260-268

4 Eriksen MT, Wibe A, Norstein J, Haffner J, Wiig JN; Norwegian Rectal Cancer Group. Anastomotic leakage following routine mesorectal excision for rectal cancer in a national cohort of patients. Colorectal Dis 2005;7(1):51-57

5 Matthiessen P, Hallböök O, Andersson M, Rutegård J, Sjödahl R. Risk factors for anastomotic leakage after anterior resection of the rectum. Colorectal Dis 2004;6(6):462-469

6 Akiyoshi T, Kuroyanagi H, Oya M, et al. Factors affecting the difficulty of laparoscopic total mesorectal excision with double stapling technique anastomosis for low rectal cancer. Surgery 2009;146(3):483-489

7 Asteria CR, Gagliardi G, Pucciarelli S, et al. Anastomotic leaks after anterior resection for mid and low rectal cancer: survey of the Italian Society of Colorectal Surgery. Tech Coloproctol 2008; 12(2): $103-110$

8 Buckley JE. Credibility and drug education: a critique and reformulation. Int J Addict 1989;24(6):489-497

9 Daams F, Wu Z, Lahaye MJ, Jeekel J, Lange JF. Prediction and diagnosis of colorectal anastomotic leakage: a systematic review of literature. World J Gastrointest Surg 2014;6(2):14-26

10 Dekker JW, Liefers GJ, de Mol van Otterloo JC, Putter H, Tollenaar RA. Predicting the risk of anastomotic leakage in left-sided colorectal surgery using a colon leakage score. J Surg Res 2011;166(1):e27-e34

11 Gorissen KJ, Benning D, Berghmans T, et al. Risk of anastomotic leakage with non-steroidal anti-inflammatory drugs in colorectal surgery. Br J Surg 2012;99(5):721-727

12 Konishi T, Watanabe T, Kishimoto J, Nagawa H. Risk factors for anastomotic leakage after surgery for colorectal cancer: results of prospective surveillance. J Am Coll Surg 2006;202(3):439-444

13 Lipska MA, Bissett IP, Parry BR, Merrie AE. Anastomotic leakage after lower gastrointestinal anastomosis: men are at a higher risk. ANZ J Surg 2006;76(7):579-585

14 Matthiessen P, Hallböök O, Rutegård J, Simert G, Sjödahl R. Defunctioning stoma reduces symptomatic anastomotic leakage after low anterior resection of the rectum for cancer: a randomized multicenter trial. Ann Surg 2007;246(2):207-214

15 Lindgren R, Hallböök O, Rutegård J, Sjödahl R, Matthiessen P. Does a defunctioning stoma affect anorectal function after low rectal resection? Results of a randomized multicenter trial. Dis Colon Rectum 2011;54(6):747-752

16 Chude GG, Rayate NV, Patris V, et al. Defunctioning loop ileostomy with low anterior resection for distal rectal cancer: should we make an ileostomy as a routine procedure? A prospective randomized study. Hepatogastroenterology 2008;55(86-87):1562-1567

17 Ulrich AB, Seiler C, Rahbari N, Weitz J, Büchler MW. Diverting stoma after low anterior resection: more arguments in favor. Dis Colon Rectum 2009;52(3):412-418

$18 \mathrm{Gu} \mathrm{WL}, \mathrm{Wu}$ SW. Meta-analysis of defunctioning stoma in low anterior resection with total mesorectal excision for rectal cancer: evidence based on thirteen studies. World J Surg Oncol 2015;13:9

19 Lucha PA Jr, Fticsar JE, Francis MJ. The strictured anastomosis: successful treatment by corticosteroid injections-report of three cases and review of the literature. Dis Colon Rectum 2005;48(4): 862-865

20 Hassan I, Larson DW, Cima RR, et al. Long-term functional and quality of life outcomes after coloanal anastomosis for distal rectal cancer. Dis Colon Rectum 2006;49(9):1266-1274
21 Hassan I, Larson DW, Wolff BG, et al. Impact of pelvic radiotherapy on morbidity and durability of sphincter preservation after coloanal anastomosis for rectal cancers. Dis Colon Rectum 2008;51(1): 32-37

22 Hyman N, Manchester TL, Osler T, Burns B, Cataldo PA. Anastomotic leaks after intestinal anastomosis: it's later than you think. Ann Surg 2007;245(2):254-258

23 da Luz Moreira A, Kiran RP, Lavery I. Clinical outcomes of ileorectal anastomosis for ulcerative colitis. Br J Surg 2010; 97(1):65-69

24 Elton C, Makin G, Hitos K, Cohen CR. Mortality, morbidity and functional outcome after ileorectal anastomosis. Br J Surg 2003; 90(1):59-65

25 Leijonmarck CE, Löfberg R, Ost A, Hellers G. Long-term results of ileorectal anastomosis in ulcerative colitis in Stockholm County. Dis Colon Rectum 1990;33(3):195-200

26 O'Riordan JM, O'Connor BI, Huang H, et al. Long-term outcome of colectomy and ileorectal anastomosis for Crohn's colitis. Dis Colon Rectum 2011;54(11):1347-1354

27 Pastore RL, Wolff BG, Hodge D. Total abdominal colectomy and ileorectal anastomosis for inflammatory bowel disease. Dis Colon Rectum 1997;40(12):1455-1464

28 Nakamura T, Pikarsky AJ, Potenti FM, et al. Are complications of subtotal colectomy with ileorectal anastomosis related to the original disease? Am Surg 2001;67(5):417-420

29 Faubion WA Jr, Loftus EV Jr, Harmsen WS, Zinsmeister AR. Sandborn WJ. The natural history of corticosteroid therapy for inflammatory bowel disease: a population-based study. Gastroenterology 2001;121(2):255-260

30 Colombel JF, Loftus EV Jr, Tremaine WJ, et al. Early postoperative complications are not increased in patients with Crohn's disease treated perioperatively with infliximab or immunosuppressive therapy. Am J Gastroenterol 2004;99(5):878-883

31 Trésallet C, Royer B, Godiris-Petit G, Menegaux F. Effect of systemic corticosteroids on elective left-sided colorectal resection with colorectal anastomosis. Am J Surg 2008;195(4):447-451

32 Bruewer M, Utech M, Rijcken EJ, et al. Preoperative steroid administration: effect on morbidity among patients undergoing intestinal bowel resection for Crohńs disease. World J Surg 2003; 27(12):1306-1310

33 Hicks CW, Hodin RA, Bordeianou L. Possible overuse of 3-stage procedures for active ulcerative colitis. JAMA Surg 2013;148(7): 658-664

34 Golub R, Golub RW, Cantu R Jr, Stein HD. A multivariate analysis of factors contributing to leakage of intestinal anastomoses. J Am Coll Surg 1997;184(4):364-372

35 Luján JJ, Németh ZH, Barratt-Stopper PA, Bustami R, Koshenkov VP, Rolandelli RH. Factors influencing the outcome of intestinal anastomosis. Am Surg 2011;77(9):1169-1175

36 Slieker JC, Komen N, Mannaerts GH, et al. Long-term and perioperative corticosteroids in anastomotic leakage: a prospective study of 259 left-sided colorectal anastomoses. Arch Surg 2012; 147(5):447-452

37 Ziegler MA, Catto JA, Riggs TW, Gates ER, Grodsky MB, Wasvary HJ Risk factors for anastomotic leak and mortality in diabetic patients undergoing colectomy: analysis from a statewide surgical quality collaborative. Arch Surg 2012;147(7):600-605

38 Eriksen TF, Lassen CB, Gögenur I. Treatment with corticosteroids and the risk of anastomotic leakage following lower gastrointestinal surgery: a literature survey. Colorectal Dis 2014;16(5): 0154-0160

39 Moss AC. Optimizing the use of biological therapy in patients with inflammatory bowel disease. Gastroenterol Rep (Oxf) 2015;3(1): 63-68

40 Krane MK, Allaix ME, Zoccali M, et al. Preoperative infliximab therapy does not increase morbidity and mortality after laparoscopic resection for inflammatory bowel disease. Dis Colon Rectum 2013;56(4):449-457 
41 Kunitake H, Hodin R, Shellito PC, Sands BE, Korzenik J, Bordeianou L. Perioperative treatment with infliximab in patients with Crohn's disease and ulcerative colitis is not associated with an increased rate of postoperative complications. J Gastrointest Surg 2008;12(10):1730-1736, discussion 1736-1737

42 Appau KA, Fazio VW, Shen B, et al. Use of infliximab within 3 months of ileocolonic resection is associated with adverse postoperative outcomes in Crohn's patients. J Gastrointest Surg 2008;12(10):1738-1744

43 Selvasekar CR, Cima RR, Larson DW, et al. Effect of infliximab on short-term complications in patients undergoing operation for chronic ulcerative colitis. J Am Coll Surg 2007;204(5):956-962, discussion 962-963

44 Selvaggi F, Pellino G, Canonico S, Sciaudone G. Effect of preoperative biologic drugs on complications and function after restorative proctocolectomy with primary ileal pouch formation: systematic review and meta-analysis. Inflamm Bowel Dis 2015; 21(1):79-92

45 Papaconstantinou I, Zeglinas C, Gazouli M, et al. The impact of peri-operative anti-TNF treatment on anastomosis-related complications in Crohn's disease patients. A critical review. J Gastrointest Surg 2014;18(6):1216-1224

46 El-Hussuna A, Krag A, Olaison G, Bendtsen F, Gluud LL. The effect of anti-tumor necrosis factor alpha agents on postoperative anastomotic complications in Crohn's disease: a systematic review. Dis Colon Rectum 2013;56(12):1423-1433

47 Gawlick U, Nirula R. Resection and primary anastomosis with proximal diversion instead of Hartmann's: evolving the management of diverticulitis using NSQIP data. J Trauma Acute Care Surg 2012;72(4):807-814, quiz 1124

48 Constantinides VA, Heriot A, Remzi F, et al. Operative strategies for diverticular peritonitis: a decision analysis between primary resection and anastomosis versus Hartmann's procedures. Ann Surg 2007;245(1):94-103

49 Vermeulen J, Akkersdijk GP, Gosselink MP, et al. Outcome after emergency surgery for acute perforated diverticulitis in 200 cases. Dig Surg 2007;24(5):361-366

50 Aydin HN, Remzi FH, Tekkis PP, Fazio VW. Hartmann's reversal is associated with high postoperative adverse events. Dis Colon Rectum 2005;48(11):2117-2126

51 Vermeulen J, Coene PP, Van Hout NM, et al. Restoration of bowel continuity after surgery for acute perforated diverticulitis: should Hartmann's procedure be considered a one-stage procedure? Colorectal Dis 2009;11(6):619-624

52 Constantinides VA, Tekkis PP, Athanasiou T, et al. Primary resection with anastomosis vs. Hartmann's procedure in nonelective surgery for acute colonic diverticulitis: a systematic review. Dis Colon Rectum 2006;49(7):966-981

53 Parks AG, Nicholls RJ. Proctocolectomy without ileostomy for ulcerative colitis. BMJ 1978;2(6130):85-88

54 Heuschen UA, Hinz U, Allemeyer EH, Lucas M, Heuschen G, Herfarth C. One- or two-stage procedure for restorative proctocolectomy: rationale for a surgical strategy in ulcerative colitis. Ann Surg 2001;234(6):788-794

55 Lovegrove RE, Symeonides P, Tekkis PP, Goodfellow PB, Shorthouse AJ. A selective approach to restorative proctocolectomy without ileostomy: a single centre experience. Colorectal Dis 2008;10(9): 916-924

56 Weston-Petrides GK, Lovegrove RE, Tilney HS, et al. Comparison of outcomes after restorative proctocolectomy with or without defunctioning ileostomy. Arch Surg 2008;143(4):406-412

57 Gorfine SR, Gelernt IM, Bauer JJ, Harris MT, Kreel I. Restorative proctocolectomy without diverting ileostomy. Dis Colon Rectum 1995;38(2):188-194
58 Remzi FH, Fazio VW, Gorgun E, et al. The outcome after restorative proctocolectomy with or without defunctioning ileostomy. Dis Colon Rectum 2006;49(4):470-477

59 Prudhomme M, Dehni N, Dozois RR, Tiret E, Parc R. Causes and outcomes of pouch excision after restorative proctocolectomy. $\mathrm{Br}$ J Surg 2006;93(1):82-86

60 Maya AM, Boutros M, DaSilva G, Wexner SD. IPAA-related sepsis significantly increases morbidity of ileoanal pouch excision. Dis Colon Rectum 2015;58(5):488-493

61 Gorfine SR, Fichera A, Harris MT, Bauer JJ. Long-term results of salvage surgery for septic complications after restorative proctocolectomy: does fecal diversion improve outcome? Dis Colon Rectum 2003;46(10):1339-1344

62 Tjandra JJ, Fazio VW, Milsom JW, Lavery IC, Oakley JR, Fabre JM. Omission of temporary diversion in restorative proctocolectomyis it safe? Dis Colon Rectum 1993;36(11):1007-1014

63 Lake JP, Firoozmand E, Kang JC, et al. Effect of high-dose steroids on anastomotic complications after proctocolectomy with ileal pouch-anal anastomosis. J Gastrointest Surg 2004;8(5):547-551

64 Lim M, Sagar P, Abdulgader A, Thekkinkattil D, Burke D. The impact of preoperative immunomodulation on pouch-related septic complications after ileal pouch-anal anastomosis. Dis Colon Rectum 2007;50(7):943-951

65 Ziv Y, Church JM, Fazio VW, King TM, Lavery IC. Effect of systemic steroids on ileal pouch-anal anastomosis in patients with ulcerative colitis. Dis Colon Rectum 1996;39(5):504-508

66 Bordeianou L, Kunitake H, Shellito P, Hodin R. Preoperative infliximab treatment in patients with ulcerative and indeterminate colitis does not increase rate of conversion to emergent and multistep abdominal surgery. Int J Colorectal Dis 2010;25(3): 401-404

67 Williamson ME, Lewis WG, Sagar PM, Holdsworth PJ, Johnston D. One-stage restorative proctocolectomy without temporary ileostomy for ulcerative colitis: a note of caution. Dis Colon Rectum 1997;40(9):1019-1022

68 Kiely JM, Fazio VW, Remzi FH, Shen B, Kiran RP. Pelvic sepsis after IPAA adversely affects function of the pouch and quality of life. Dis Colon Rectum 2012;55(4):387-392

69 Chen J, Wang DR, Zhang JR, Li P, Niu G, Lu Q. Meta-analysis of temporary ileostomy versus colostomy for colorectal anastomoses. Acta Chir Belg 2013;113(5):330-339

70 Güenaga KF, Lustosa SA, Saad SS, Saconato H, Matos D. Ileostomy or colostomy for temporary decompression of colorectal anastomosis. Cochrane Database Syst Rev 2007;(1):CD004647

71 Güenaga KF, Lustosa SA, Saad SS, Saconato H, Matos D. Ileostomy or colostomy for temporary decompression of colorectal anastomosis. Systematic review and meta-analysis. Acta Cir Bras 2008; 23(3):294-303

72 Rondelli F, Reboldi P, Rulli A, et al. Loop ileostomy versus loop colostomy for fecal diversion after colorectal or coloanal anastomosis: a meta-analysis. Int J Colorectal Dis 2009;24(5):479-488

73 Tilney HS, Sains PS, Lovegrove RE, Reese GE, Heriot AG, Tekkis PP. Comparison of outcomes following ileostomy versus colostomy for defunctioning colorectal anastomoses. World J Surg 2007; 31(5):1142-1151

74 Montedori A, Cirocchi R, Farinella E, Sciannameo F, Abraha I. Covering ileo- or colostomy in anterior resection for rectal carcinoma. Cochrane Database Syst Rev 2010;(5):CD006878

75 Bakx R, Busch OR, Bemelman WA, Veldink GJ, Slors JF, van Lanschot JJ. Morbidity of temporary loop ileostomies. Dig Surg 2004;21(4):277-281

76 Williams NS, Nasmyth DG, Jones D, Smith AH. De-functioning stomas: a prospective controlled trial comparing loop ileostomy with loop transverse colostomy. Br J Surg 1986;73(7):566-570 